IRA-International Journal of Education \& Multidisciplinary Studies ISSN 2455-2526; Vol.05, Issue 02 (2016)

Pg. no. 129-132

Institute of Research Advances

http://research-advances.org/index.php/IJEMS

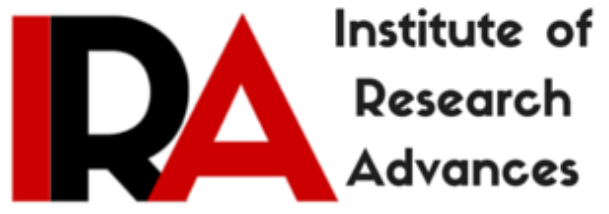

\title{
Introducing the Work Horses of Thermodynamics using Flexagon
}

Nitin V. Bhate

Associate Professor

Chemical Engineering Department, Faculty of Technology and Engineering, The Maharaja Sayajirao University of Baroda, Vadodara, Gujarat, India.

Type of Review: Peer Reviewed.

DOI: http://dx.doi.org/10.21013/jems.v5.n2.p8

\section{How to cite this paper:}

Bhate, N. (2016). Introducing the Work Horses of Thermodynamics using Flexagon. IRA International Journal of Education and Multidisciplinary Studies (ISSN 2455-2526), 5(2), 129-132. doi:http://dx.doi.org/10.21013/jems.v5.n2.p8

(C) Institute of Research Advances

\section{(cc) EY-NC}

This work is licensed under a Creative Commons Attribution-Non Commercial 4.0 International License subject to proper citation to the publication source of the work.

Disclaimer: The scholarly papers as reviewed and published by the Institute of Research Advances (IRA) are the views and opinions of their respective authors and are not the views or opinions of the IRA. The IRA disclaims of any harm or loss caused due to the published content to any party. 


\begin{abstract}
Flexagon is one of the oldest paper folding techniques. This has been extensively used by artists to make different shapes and designs. This tool has been successfully used to introduce the fundamentals of thermodynamics to Undergraduates as well as High School children. The flexagon focuses on the first law of thermodynamics and the interplay between Internal energy, Enthalpy, Heat and Work. This tool not only makes the teaching-learning process interesting but also helps the students memorize these concepts easily.
\end{abstract}

Keywords: Thermodynamics, Heat, Work, Internal energy, Enthalpy, Flexagon, Learning

\title{
Introduction
}

Flexagon derives its name from the fact that it can be 'flexed' and folded to reveal different faces. Its use has been to a larger extent to draw different shapes on the faces or put different colours on the faces so that it reveals different designs or colors when flexed. Different types of flexagons are named based on the number of sides and faces. For example, a trihexaflexagon has three faces and six sides. This was accidently discovered by Arthur Stone in his early twenties while folding paper strips in different ways. Several mathematicians have used flexagons to simplify the mathematical concepts and make it interesting to the students [1-3]. Flexagons have also been used to introduce food chain and life cycles [4]. Recently a topic related to Gas-Liquid reactions in Chemical Reaction Engineering was simplified using flexagons [5].

Thermodynamics is one of the fundamental courses in Chemical and Mechanical Engineering. Some concepts of thermodynamics are also introduced in physics at the High school level. This subject being abstract makes students shy away from it. It has been tagged as an extremely scary subject. One of the reasons is that it has many equations which need to be remembered. Although there exists a logical and fundamental way of learning the subject, many students end up cramming the equations. The first law of thermodynamics also called energy balance or law of conservation of energy deals with the interconversion of internal and external energies [6]. The latter include potential and kinetic energies. However, in majority of engineering calculations change in internal energy and enthalpy are important entities. Heat and work are other two important entities which form a part of the first law of thermodynamics. They always appear at the system-surrounding boundary and hence are called energies in transit. They are the effect of the various processes occurring in the system or the conditions prevailing in the system namely, Isobaric, Isochoric, Isothermal and Adiabatic. The changes in the internal energy and enthalpy and the magnitudes of heat and work will be different for the various processes mentioned above. Hence these four entities are called the 'Work Horses of Thermodynamics'. The students are expected to remember the equations for the computation for different processes. A flexagon has been developed to summarize these equations and help them remember without cramming.

\section{Procedure for making the Flexagon}

The flexagon can be made with a strip of paper with length to width ratio of 2 . If an A4 size paper is used, the dimensions can be $20 \mathrm{~cm} \times 10 \mathrm{~cm}$. The width is divided into 4 equal parts and the length into eight equal parts with light markings with pen or pencil. Two diagonals are drawn in this rectangle starting from one corner to the opposite end. Three parallel lines are sketched on either side of the diagonals. These can be easily drawn from the intersection of the vertical and the horizontal lines mentioned above and as shown in Figure 1. This template can be sketched either in MS Word, MS Power Point or MS Paint. 
The equations for the work horses for the four processes mentioned above are included in the template. The content is included in the six vertical sections and the two horizontal sections as shown in Figure 1. It is also evident that the intersection of the diagonals gives rise to seven full diamonds, four half diamonds along the length and six half diamonds along the width. The content is written in the respective diamonds and is split suitably in two half diamonds. Once the template is ready with the content it is folded systematically. The paper is folded inwards along the dotted horizontal lines. It is then oriented in such a way that the side with the folds appears in the front. Folds along the vertical lines give rise to eight sections. Further it is folded along the diagonals from bottom left to top right and top left to bottom right. The eighth section and about one-fourth of the seventh section is cut. The seventh section is inserted in the pocket of the first section. This gives rise to a prism. The top and the bottom edges of the prism are creased and pushed inwards. The flexagon is ready (Figure 2). It is rotated several times to reinforce the creases. This tool was tried out with the students studying in the Second year of Chemical Engineering at the Maharaja Sayajirao University of Baroda. There was an overwhelming response from the students.

\section{Conclusion}

The making of the flexagon not only instills creativity by also gives an inner satisfaction. Flexing this tool gives enjoyment along with understanding the concepts of thermodynamics. The equations for the Work Horses of thermodynamics can easily be memorized with this tool. Moreover, it can also help recapitulate the equations while preparing for the examination. The positive feedback from the students makes it a useful tool in the teaching-learning process and can be explored for teaching other topics as well. Since it takes only a few minutes to make a flexagon it can be integrated with the classroom teaching.

\section{References}

[1] Chapman, P. B. (1961) "Square Flexagons." Math. Gaz. 45, 192-194

[2] Cundy, H. and Rollett, A. (1989). Mathematical Models, 3rd ed. Stradbroke, England: Tarquin Pub.

[3] Pappas, T. (2001). The Joy of Mathematics: Discovering Mathematics, Wide World Pub.

[4] Gupta, A. (2007). "Flexagons" in Little Science, Eklavya Pub.

[5] Bhate, N. (2016), 'Learning Gas-Liquid Reactions using Flexagons', Int. Edu. Res. J., Vol. 2 (10), 20-21.

[6] Smith, J. M., van Ness, H. C., Abbott, M. (2001), 'Introduction to Chemical Engineering Thermodynamics', McGraw Hill, New York. 


\section{(Figures \& Tables)}

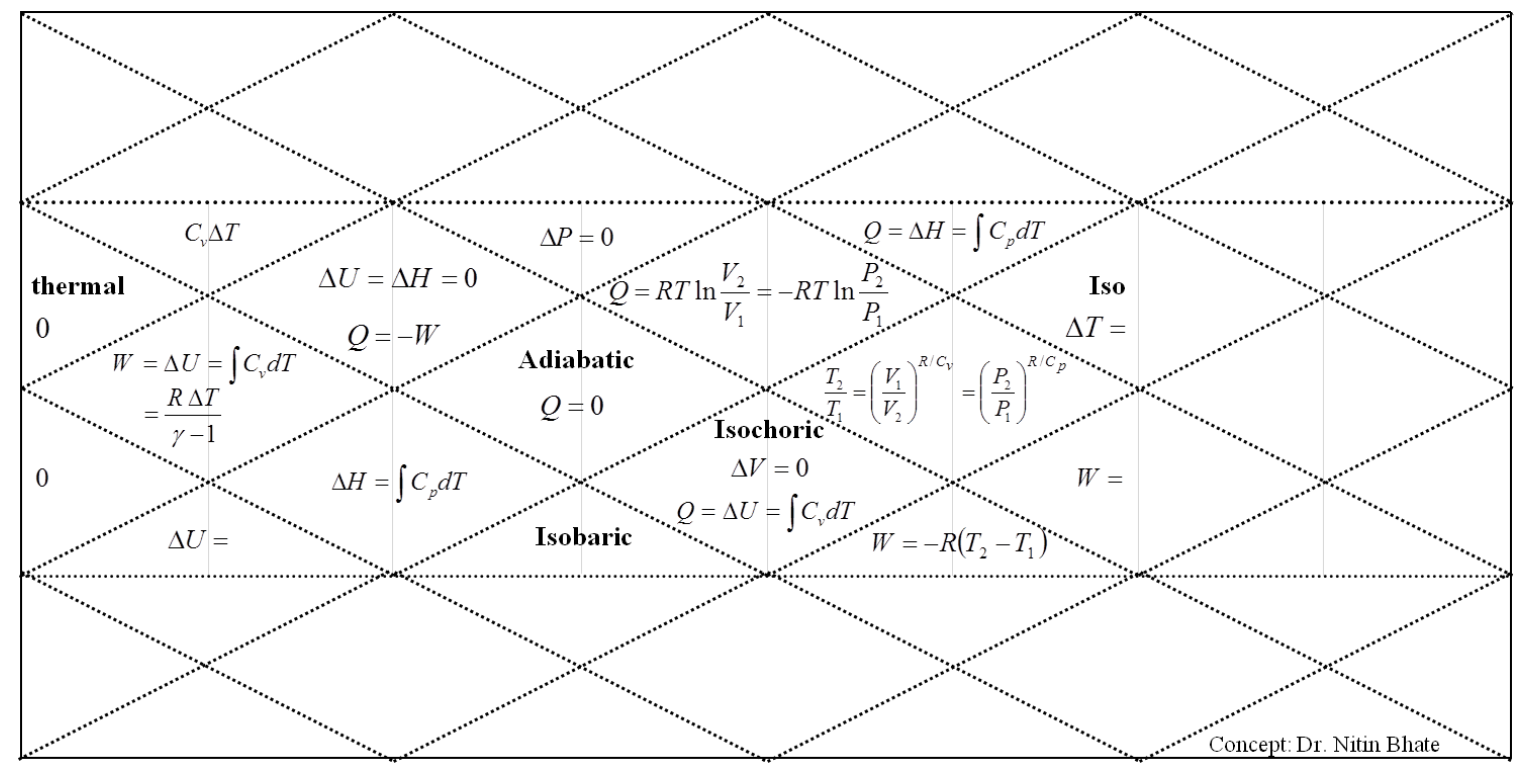

Figure 1: Template for the Work Horses of Thermodynamics

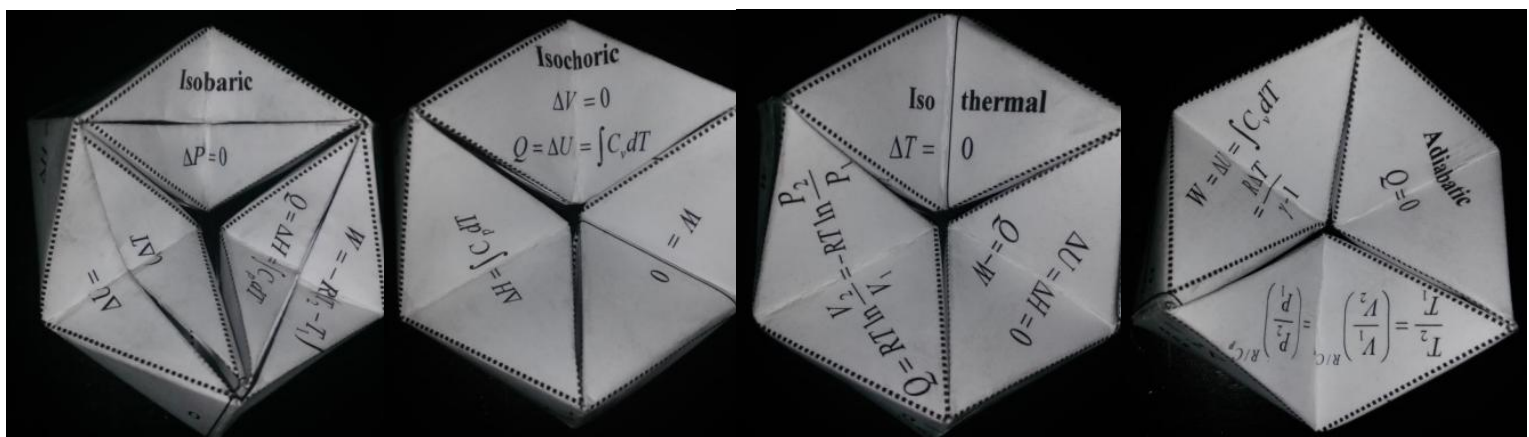

Figure 2: Flexagon for the Work Horses of Thermodynamics 